\title{
USING VIDEOS IN THE TEACHING OF LISTENING
}

\author{
Lalu Dwi Satria Ardiansyah \\ Lecturer at Nahdlatul Ulama University NTB \\ e-mail: laludwisatriaardiansyah@gmail.com
}

\begin{abstract}
This research aims to investigate the impact of using videos as audio-visual aids for teaching listening for ESL. It was conducted from March 15, 2018 up to May 28, 2018. The population of this study was the first semester of University of Nahdlatul Ulama NTB, and from this population, two classes were selected as the sample. This research employed true experimental research method with two groups, an experimental group (EG) and a control group (CG). The EG was taught by using authentic video, while the CG used audio Compact Disc (CD) as the teaching aid most often used by ESL teachers in teaching listening. In collecting the data, the writer used tests as the instrument, and in analyzing the data collected, Analysis of Variance (ANOVA) computer software was employed. The mean score of the results from the post-tests from the EG at 75 was higher than that of the control group at 64 . Moreover, the t-test for the EG was higher than that for the CG $(11.51>4.06)$ which meant that the improvement in the EG was significantly higher than the listening achievements of the CG. The EG students taught by using authentic video achieved higher results in listening than the CG ones taught by audio compact disc (CD). As a result, the alternative hypothesis was accepted and null hypothesis was rejected which meant that there was a significant improvement in terms of listening achievements after the use of authentic videos treatment.
\end{abstract}

Keywords: Teaching Listening, Authentic Video, Comprehension.

\section{INTRODUCTION}

The ever-increasing accessibility of technology and the fast pace of technology change in recent years bring changes into many aspects of life, including the teaching and learning of English as a Foreign Language (EFL) in Indonesia. Teaching generation $\mathrm{Z}$, those who are born in the advanced/modern technological era and are very adept in using technology, requires different approaches, methods, materials, and so on in teaching. In the teaching of listening, one of the most obvious changes are in the availability of materials and modes of learning, ranging from audio/radio, video to the internet, which bring a vast array of possibilities into the listening instruction.

As the Cinderella skill in second language learning, an important but somehow a forgotten one, listening is, recent years, not as extensively studied as other skills although there has been much increased attention to it (Field, 2008; Rost, 2002; Brown, 2002; Flowerdew \& Miller, 2005; Richards \&Renandya, 2002). With the advance of technology, however, there have been many studies on the use of technology to improve the EFL teaching and learning, including those confirming the benefits and effectiveness of audiovisual in learning, including in learning listening (Rahmatian \& Armium, 2011; Borko et al, 2008; Richardson \& Kile, 1999; Seago, 2003; and Wang \& Hartley, 2003, as cited in Berk, 2009). The benefits include stimulation and facilitation in the learning of a foreign language and understanding of another culture by providing vicarious contact with speakers of the language through both audio and visual means (Cahyono \& Widiati, 2009), bringing real world into the class, contextualizes language naturally and enable learners to experience authentic language in a controlled environment (Cakir, 2006), as well as providing kinesic knowledge (Flowerdew \& Miller, 2005).

However, despite many benefits of audiovisual, including videos, in learning listening, many teachers have not used it; many of them only use audio. Flowerdew and Miller points out that "the typical reliance on audio recordings for the teaching of listening comprehension reduces the exposure of learners to kinesic meaning. Greater use of 
video and real-life interaction, on the other hand, provides learners with exposure to this important dimension of meaning." (2005; 4546). Even when teachers use videos, many only play the video in the class for the whole duration without any well-planned tasks/exercises to maximize the potentials. Two of most cited reasons are not knowing how to use/integrate the video into their teaching and the unavailability of appropriate materials with videos to use in their class. These two problems will be solved if teachers know the techniques to integrate the video materials for teaching listening. This paper will discuss the techniques and ways to use videos in the teaching of listening, after first discussing the formats of teaching listening with video and the benefits of videos to improve listening comprehension.

\section{Research question}

Based on the problems found at the first semester of University of Nahdlatul Ulama NTB, the following question was formulated: "Will there be any significant difference in listening achievements between students taught listening using authentic videos and those who are taught using audiocompact discs (CDs)?"

\section{A. Research Objective}

According to the research question, the objective of this study was to discover if there will be any significant difference in listening achievements between students taught listening using authentic videos from those taught using audio - compact discs (CDs).

\section{REVIEW OF RELATED LITERATURES The Teaching of Listening}

Listening is one of the fundamental skills. It refers to a complex process that makes it possible for us to understand spoken language (Ross, 1990). It is a medium through which children and adults gain a large portion of education - information, understanding the world and human affairs, ideas, sense of values, and appreciation. Listening comprehension is an important language skill that language learners need to develop. Furthermore, the development of all other language skills is interwoven with listening skills. Listening is not only a skill area in language performance, but also a critical means of acquiring a second language (L2). It is said to be at the heart of both first and second language learning (Vandergrift, 2007).

In listening, one should also take into account the fact that every individual has their own listening strategies and that they may have different purposes while listening, as listed in Rahmatian and Armium (2011) such as listening for hearing, listening for detecting, listening for selecting, listening for identifying, listening for recognizing, listening for disambiguating, listening for reformulating, listening for synthesizing, listening for doing, listening for judging, and other listening objectives such as listening for reconstructing, guessing, anticipating, transposing, deducting, revising a judgment, classifying, etc. For those purposes, the listener may employ different models of listening process.

There are three models of the listening proces as mentioned in Flowerdew and Miller (2005), namely bottom-up model, top-down model, and interactive model. The bottom-up view sees listeners as tape recorders, whereas top-down view considers listeners as model builders. The former suggests that listeners take in and store oral messages in much the same way as a tape-recorder, whereas the latter acknowledges the more active role that listeners play as they construct an interpretation of oral messages. As also indicated by Nunan (1991), the bottom-up view refers to the idea that listeners segment the stream of speech into its constituent sounds, link this together to form words, chain the words together to form clauses and sentences, and so on (p. 17). This processing model assumes that listening is a process of decoding the sounds in a linear fashion, from the smallest meaningful units to complex texts (Nunan, 2002). As the process is linear, meaning is derived as the last step in the process.

In contrast, the top-down view allows listeners to bring knowledge from outside the text to the task of interpreting and comprehending the text itself. This view implies an important point that meaning does not reside exclusively within the words on the oral messages (Nunan, 1991: 18). The 
knowledge inside the head of listeners contributes to understanding. In other words, the processing of language information comes through an internal source, retrieved from a bank of prior knowledge and global expectations. Therefore, as Brown (2006: 2) suggests that one very important idea for teaching listening is that listening courses must make use of students prior knowledge in order to improve listening comprehension. In other words, listening is an active process of constructing (or reconstructing) the original meaning of the speaker using incoming sound as clues (Nunan, 2002).

Research, however, suggests that the way listening works is not exclusively bottom-up, nor is it to be merely top-down, but interactive. Successful listeners seem to be those who can utilize both bottom-up and top-down knowledge, combining the knowledge outside the head with that inside the head. Under this view, listeners are considered as active players in constructing the oral text, employing various strategies in reconstructing messages. In other words, successful listening involves the integration of information encoded in the message itself with broader knowledge of the world (Nunan, 1991: 25).

\section{A. Benefits of Videos for Teaching Listening}

Videos possess many potentials to be used in teaching listening to improve the acquisition of listening skills. Thus, it should not be regarded as merely a peripheral 'extra' in a listening class; on the contrary, they can function as the core content and become an integral part of the curriculum (Sommer, 2001, in Kusumarasdyati (2006). With four pedagogical values of videos in the teaching listening: motivation, visual supports for comprehension, authentic language, and cultural contexts. Videos draw learners' interests and motivate them to learn while also learning the language components exposed in the videos. Videos also provide visual support, such as facial expressions and gestures, to help learners' comprehension. Therefore, it can simulate the dialogs in real situations where such virtual supports are almost always present to accompany verbal exchanges. Besides, videos provide exposure to authentic language in authentic settings which is valuable in assisting the students to participate in the real conversations because the the rate of delivery, the choice of words and the tendency of truncations (such as elliptical structures and contractions) are very similar to those in real life, as opposed to the exchanges in the majority of commercial listening materials, which may sound quite artificial. Lastly, videos present cultural contexts of the conversations which enhance more appropriate use of language and preventing cross-cultural misunderstandings and can be a useful start to investigate the target culture. All these advantageous aspects of movies as listening materials provide sufficiently strong ground for language educators to have them shown in EFL instructions.

Similarly, Harmer (2007: 308) mentions several benefits of using video (film clips on videos, DVDs or online). First, it provides 'language in use', allowing the students to see paralinguistic behavior such as how intonation matches facial expression and what gestures accompany certain phrases, and thus they can pick up a range of cross-cultural values. Second, it gives students perspectives of "a whole range of other communication worlds", such as how different people stand (in terms of proximity) when they talk to each other and types of food they eat. Third, it makes students easier to understand unspoken rules of behavior in social and business situations.

More detailed advantages of audiovisual (video) for instruction are mentioned in Cakir (2006) such as:

1. It provides authentic language input.

2. It can easily be used; teacher can step in the process whenever he wishes; he can stop, start and rewind to repeat it for several times where necessary. Any selected short sequence from the programme can be utilized for intensive study. To pay special attention to a particular point in the programme it is possible to run in slow motion or at half speed or without sound.

3. The learner can concentrate on the language in detail and interpret what has 
been said, repeat it, predict the reply and so on. The learner can also concentrate in detail on visual clues to meaning such as facial expression, dress, gesture, posture and on details of the environment. Even without hearing the language spoken clues to meaning can be picked up from the vision alone. Using visual clues to meaning in order to enhance learning is an important part of video methodology.

4. It gives students practice in interpreting attitude because the listener can concentrate on both the verbal message and the visual clues to meaning. The rhythmic hand and arm movements, head nods, head gestures are related to the structure of the message.

5. It gives the students a general idea of the culture of the target language. It may be enjoyable for the learners to have something different for language learning apart from the course books and cassettes for listening.

Using audiovisual material (video), however, may have disadvantages are such as high cost and maintenance, inconvenience and fear of technology, the poor quality of the sound and vision, and the preparedness of the teacher in using the video (Cakir, 2006). These problems may be tackled by teachers being prepared and well-acquinted with technology and having a technicians to help in the preparation.

\section{B. Formats of Using Videos in the Teaching of Listening}

The general format of teaching listening is as what Field (2008) called as the current format, as in Figure below.

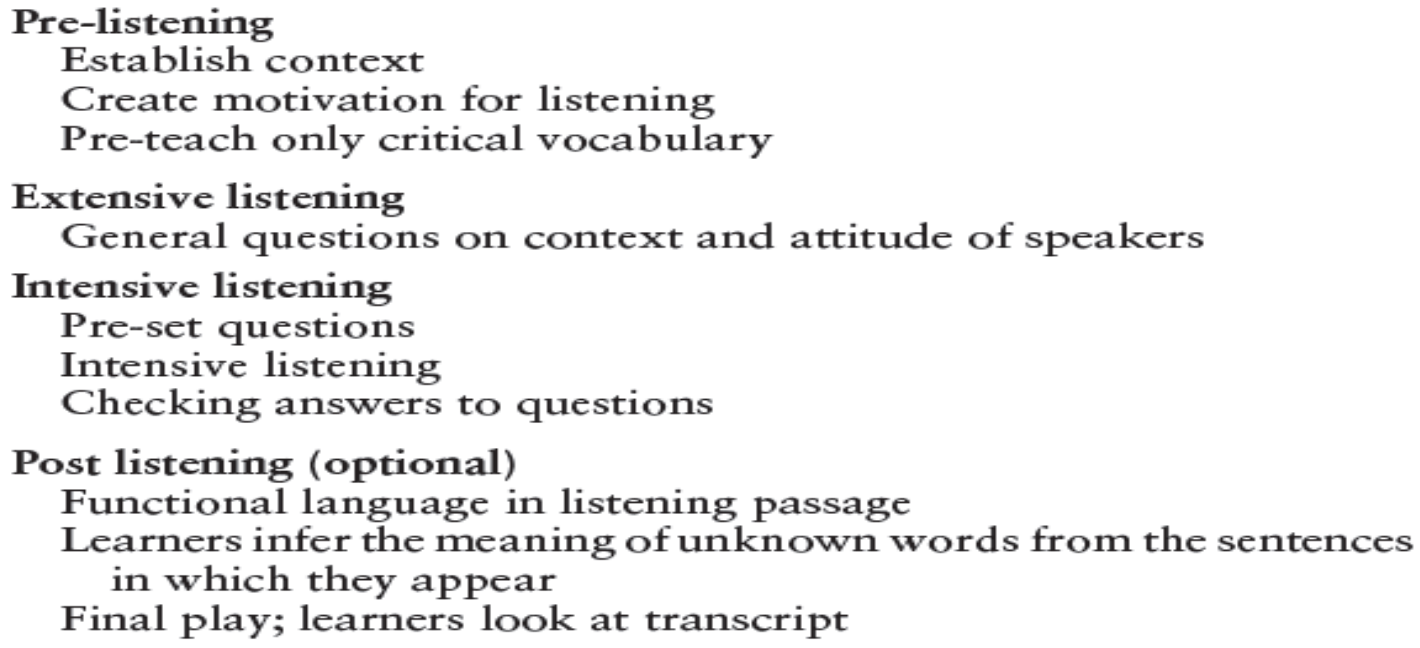
in which they appear

Figure 1. Current format of a listening lesson (Field, 2008:17)

In pre listening, only 'critical words', or those words without which the recording could not be understood are taught (p. '17). It is done to give more attention to listening itself, to prepare the students with the real-life listening, and to direct the students more to the meaning of the text than to the language of the text. In addition, students' motivation need to be encouraged and created in this stage to give learners the right mental set for what the listening passage is likely to contain. Meanwhile, during listening, the questions are given before the second play of the cassette to ensure that the learners know in advance what they are listening for. Then, the teacher allows learners time to write their answers and then checks them with the class as a whole after they compare them with their pairs.In post listening, functional language used in the text is used as contextualized examples of language functions. Prominent features in the listening passage need some attention and pausing to practice them. In addition, teachers gives practice on inferring vocabularies used in the listening passage by replaying the sections of the listening passage which contain them. The current format is as in the following figure.

\section{Format of teaching listening with videos}

In using videos for teaching listening, the format is adjusted into pre-viewing, while- 
viewing, and post-viewing. Each phase will be described as follows (Kusumarasdyati, 2006).

\section{a. Previewing}

At this beginning stage the teacher spends a sufficient amount of time helping the learners build the appropriate schemata to facilitate comprehension to enable the learners relate the knowledge they already possess and the one to be acquired, making the acquisition occur more smoothly. Generally the previewing stage consists of two activities, namely, introducing the theme of the movie and pre-teaching the key vocabulary (Allan, 1985; Tomalin, 1986; Sheerin, 1982). Additionally, some teachers believe it might be quite fruitful to familiarize the learners with the main characters of the movie prior to viewing.

At the beginning of the session the teacher briefly describes the theme underlying the whole plot of the movie and then administers a worksheet and an answer sheet. The learners scan the items in the worksheet for a few a minutes to familiarize themselves with the learning activities to be carried out before, during and after viewing the movie. As the film is presented with subtitles, before watching it the learners needed to read the brief description of the theme and the main characters. Since the lexical items would be a part of the while-viewing, key vocabulary is not pretaught.

\section{b. While-viewing}

Immediately after the previewing stage, the teacher engages them in the core activity: viewing the movie. While doing so, students should answer some items in the worksheet in written form, containing some questions to check their comprehension and some others to improve their lexical knowledge. First, allow the students one minute or two for a quick review of the scenes and the questions written in the worksheet, so that they have an idea of the scenes to watch in the entire movie and can focus their attention on the information to seek. Next, play the movie, and after each scene mentioned in the worksheet pause for 15 to 60 seconds, depending on the length of the required answer. During this pause, have them supply a correct, brief answer. Occasionally, the video is played twice when after viewing a scene once the students still found it quite difficult to recognize the words spoken by the characters or understand their exchange

Each item consists of a brief description of the scene to refer to (written in italics) and one or more questions to be answered. The description of the scene assisted the learners to direct their attention to a particular spot in the movie which is related to the question(s) being asked. The comprehension and vocabulary questions are written in similar fashion - questions preceded by a clue of the scene-unless the questions need to be answered by grasping the ideas and/or inferring the answers from the entire movie. In the latter case, the description of the scene is occasionally not required.For instance, the label of 'in the bus' above item number 1 in the worksheet for A Walk in the Cloudsprompts the students to become more alert when they watch the scene of a bus on the screen and know immediately what specific information to look for.

When there is time constraint, a particular video may need to be presented in two sessions, and this split turned out to be an advantageous point in the lesson rather than otherwise as it catered for an opportunity of stimulating the learners' imaginative capability by having the learners predict how the story would end on the answer sheet.

\section{c. Postviewing}

In this this phase, the learners (1) verify and review the written result of their prediction against the actual ending, (2) examine the diversity across cultures, either by identifying how the target culture in the film differed significantly from their own culture, or (3) making use of the cultural issues depicted in the films. Figure 2 is an example of such an item taken from the worksheet for A Walk in the Clouds, examining the different cultures of people living in the same countrywhich may cause their different views of the world.

The figure below exemplify the activities in the whole phases. 


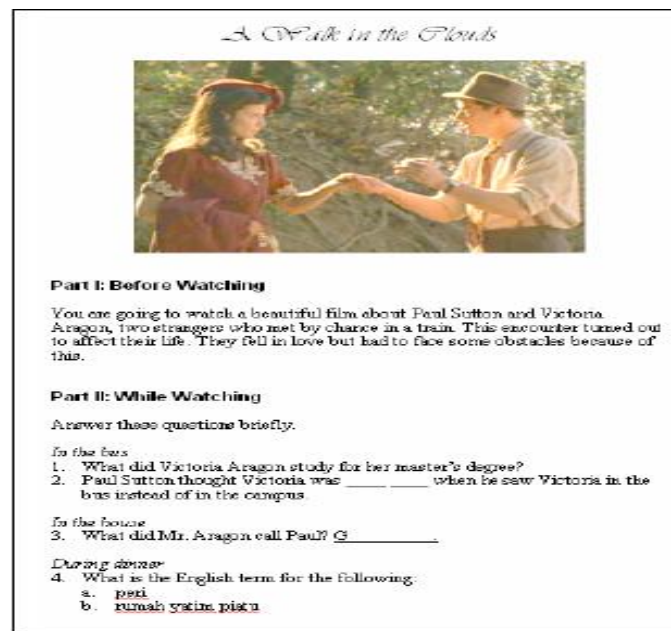

Figure 2. Sample Worksheet

\section{Techniques of Using Videos in Teaching Listening}

Using videos in teaching listening can be done in several ways. King (2002, in Kusumarasdyati, 2006) suggests four approaches: sequential, single-scene, selective, and whole-film. In sequential approach, the teacher exposed scene-by-scene or one segment of the movie at one time. In contrast, the single-scene approach requires the teacher to use only one particular scene for the language instruction. The selective method involves the viewing of a few scenes chosen by the teacher from one movie. Lastly, in the whole-film approach the teacher shows the movie in full length within a single viewing. The choice of approach is dependent on mainly on the instructional objectives and the characteristics of the students.

There are also two options in presenting the videos, with closed captions and without closed captions (King, 2002 in Kusumarasdyati, 2006). Closed captions are

\section{Table 1: Advantages of closed captions and without closed captions in presenting videos}

\begin{tabular}{|c|c|}
\hline Closed captions & Without closed captions \\
\hline $\begin{array}{l}\text { - follow a plot easily and get involved in plot } \\
\text { development. } \\
\text { - learn to pronounce proper nouns in different } \\
\text { disciplines. } \\
\text { - acquire colloquial, context-bound expressions } \\
\text { and slang. } \\
\text { - process a text rapidly and improve rapid reading. } \\
\text { - keep up with closed captioning that accompany } \\
\text { the native-speed spoken English. } \\
\text { - provide relaxing, stress-free learning } \\
\text { environments where students can comprehend } \\
\text { jokes and have a few hearty laughs. }\end{array}$ & $\begin{array}{l}\text { - help students develop a high tolerance of } \\
\text { ambiguity. } \\
\text { - enhance students' listening strategies such } \\
\text { as guessing meaning from context and } \\
\text { inferring strategies by visual clues, facial } \\
\text { expressions, voice and sound track. } \\
\text { - promote active viewing and listening for } \\
\text { key words and main ideas. } \\
\text { - motivate students to make use of authentic } \\
\text { English material on their own. } \\
\text { - provide students with the opportunity to } \\
\text { experience a great sense of accomplishment }\end{array}$ \\
\hline
\end{tabular}

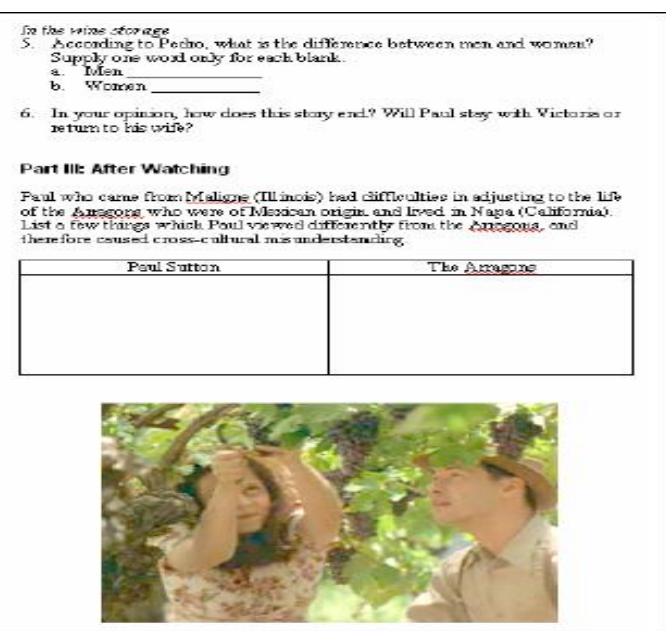

texts written on the screen to transcribe the conversation of the speakers in the movie and indicate any other sounds as well, like music, lyrics, or phone ring. Whereas closed captions include any sounds, subtitles contain only the words articulated by the speakers. Both, however, may be available in the original language only or translated in several other foreign languages also. The teacher may opt to present the movie with or without closed captions for each of them has their own advantages as presented in the following table (King, 2002, in Kusumarasdyati, 2006). Most importantly, whichever option an educator chooses to make, it is essential that the students receive guidance in attempting to grasp the didactic meanings from the aural and visual input; otherwise, the viewing would be an entertaining event without any educational values. 


- learn different strategies for processing and self-assurance.
information.

Many experts (such as Harmer, 2007; Cakir, 2006; Kusumarasdyati, 2006) have suggested a lot of techniques to use video in teaching listening. Some of the suggested techniques are similar to one another. This paper will only discuss several of them. To promote engagement and expectations in listening, Harmer (2007: 309-310) suggests several listening routines/techniques, namely (a) pictureless listening (language):The teacher covers the screen and turns the monitor away from the students or turns the brightness control right down. The students then listen to a dialogue and have to guess such things as where it is taking place and who the speakers are(e.g. age, appearance); (b) Pictureless listening (music):It is used where an excerpt has a prominent music tract. Students can listen to it and then say - based on the mood it appears to convey - what kind of scene they think it accompanies and where it is taking place; (c) Pictureless listening (sound effects):In a scene without dialogue students can listen to the sound effects to guess what is happening(e.g they might hear the lighting of a gas stove, eggs being broken and fried) and then tell the story they think they just have heard; (d) Picture or speech: the class i divided in two so that half of the class faces the screen and the half faces away. Students who can see the screen have to describe what is happening to the students who cannot. This forces them into immediate fluency while the non-watching students struggle to understand what is going on, and is an effective way of mixing reception and production in spoken English. Halfway through an excerpt, the students can change around; and (e) Subtitles: The teacher can provide subtitles for the film extract being shown, or turn down the sound while watching the film extract with subtitles. Then, especially with the subtitles in the students' L1 language, the teacher stops the film every time a subtitle appears and asks the students to say what they think the characters are saying in English. When using DVDs with the option of turning off the subtitles, the teacher can ask the students to say what they would write for subtitles and then they compare theirs with what actually appears. To awake students' curiosity, Harmer (2007: 306-308) provides five viewing techniques namely: Fast forward, Silent viewing (for language and music), Freeze frame, and Partial viewing (further discussion on these techniques is provided in the subsequent discussion since most of them are of similar nature).

Furthermore, Cakir (2006) provides some practical techniques for audiovisual material, especially video in classroom such as (a) active viewing: Before starting the presentation the teacher writes some key questions on the board about the presentation so that the students get an overview of the content of it. After viewing the questions the students answer the questions orally, or the students may take notes while viewing. For more detailed comprehension students are provided a cue sheet or viewing guides and let them watch and listen for specific details or specific features of language; (b) Freeze framing and prediction: Teacher freezes the picture when he or she wants to teach words and expressions regarding mood and emotions, to ask questions about a particular scene, or to call students' attention to some points. By freezing the scene the students can be asked what is going to happen next. So they speculate on what will happen in the next act; (c) Silent viewing: the video segment is played with the sound off using only the picture and then students have to guess what is happening and what the characters might be saying or ask students what has happened up to that point. Finally, video segment is replayed with the sound on so that learners can compare their impressions with what actually happens in the video; (d) Sound on and vision off activity: play a section of a video unit and remove the visual element from the presentation by obscuring the picture so that students can hear only the dialogue but unable to see the action. Through this activity the students predict or reconstruct what has happened visually depending only what they hear; (e) Repetition and role-play: When there are some difficult language points in the 
video unit, a scene on video is replayed with certain pauses for repetition either individually or in chorus. When students have a clear understanding of the presentation, they are asked to act out the scene using as much of the original version as they can remember. When students become confident with role playing and are sure of vocabulary and language structures, more creative activity can be introduced in which they are asked to improvise the scene to fit their views of the situation and the characters they are playing; (f) Reproduction activity: After students have seen a section, students are asked to reproduce either what is being said, to describe what is happening, or to write or retell what has happened; and (g) Dubbing activity: when students have the necessary language competence, ask them to fill in the missing dialogues after watching a sound-off video episode.

Other similar techniques are suggested by McKinnon (n.d.), such as (a) Split viewing: Some students see and hear a sequence; others only hear it. A variety of activities can then follow based on an information-gap procedure; (b) Vision on/ Sound off: Students view a scene with the sound turned off. They then predict the content of the scene, write their own script and perform it while standing next to the television. After the performances students watch the scene with the sound on and decide which group was the funniest or the nearest to the original. This is a good fun exercise; (c) Observe and write: Students view a scene (this always works better if there is a lot happening) then write a newspaper article on what they have witnessed; (d) Video dictogloss: Students watch the scene a few times and write the main words and short phrases that a particular character says. Each group is given a character and is encouraged to listen and exchange information, this usually works better if there are two characters in the scene. Working with someone from a different group, they then write the script for the scene, incorporating both characters. As they will not have managed to write down the whole script from the listening exercises they will have to use their imagination and fill in the gaps. This gives them an excellent opportunity to work on grammar; and (e) Watch and observe: Students watch a scene from a film which has lots of things that they can see and therefore write in their vocabulary books. You can teach and test your students' vocabulary by asking a series of true/ false questions and asking them to put a series of events in order. This is a good lesson for lower levels because students only have to focus on a minimum of spoken dialogue.

A further suggestion is using video to lead to students' video production (Chu, 2006). While viewing videos can be done with playing only certain clips or scenes, and teachers canhave their students do activities with them. Students will use the target language tocomplete activities, such as summarizing what they see, what they hear, and whatthey think will happen in the film etc. In further activities of viewing videos, teacherswill not show the ending part of film, and they will have students create an ending forit. Students will use video recorders to videotape their performances and evaluate onthe film. Students can prepare for their filming by writing the scripts, practicing/acting out and filming their performance. They can evaluate their own performancesafterwards. Students canlisten and watch themselves when they speak their target language. This can helpthem to pay attention to their pronunciation, intonation, loudness, and mistakes, etc.For example, students practice pronunciation and intonation byusing video recorders. Students also can pay attention to their sentence constructionsand grammar. This is a way that students focus on language. Students can selfmonitor their own mistakes by using video recorders. Normally, teachers cannot helpevery single student correct his or her mistakes during the class period because therecan be more than 15 to 20 students in one class. Therefore, as students produce theirown videos and watch them after filming that can help students do self-correction.

\section{E. Sample Lessons of Using Videos in Teaching Listening McKinnon in} his article(http://www.onestopenglish.com/suppo rt/methodology/teaching- 
technologies/teaching-technologies-teachingenglish-using-video/146527.article) offers advices and suggestions on on how to teach English using video and provide sample lesson plans to use. In this paper, some of his suggestion will be discussed to provide examples of the activities. These lesson plans refer to specific films which have been released recently, however, they could be adapted for use with a similar scene in a different film depending on availability. a. Split viewing

In this particular lesson those students who see and hear the clip from Pearl Harbour are eyewitnesses to the dramatic event, the others are journalists working for a radio station who have to conduct a live interview. Students are not asked to pay attention to any specific dialogue but relay their experience of the scene they have just witnessed to a horrified public. This is particularly good for past tenses and intermediate levels.

Level: Pre-intermediate, Intermediate, Upper intermediate

\section{Split Viewing}

Film: Pearl Harbour (adlaptable to other films)

Language focus: practising narrative tenses.

This lesson uses the scene where the Japanese planes first fly into Pearl Harbour and takes in the first part of the action. The students have a lot to observe in the six minutes thirty seconds of scene.

From the scene where the planes first fly towards the island to when the sleeping nurse wakes up and shouts "Everybody to the hospital!"

Stage One: Pre-viewing task: Ask your students to answer the following questions in pairs:

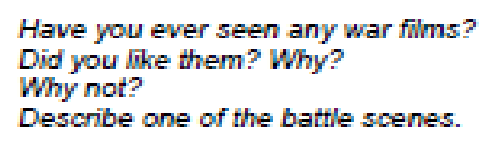

Stage Two: While-viewing task: Split the class into two groups, one group will watch and listen to the scene; the other will only listen. Explain to those who watch that they must observe what happens, making notes if necessary. and be ready to explain to the others what happened; to the others say they must listen to the action and write $a$ few questions about what they can hear but cannot see. Play the video clip.

Stage Three: Post-viewing task: Give each group of students the appropriate role-play card (attached). They will need some time to complete the task. After they have finished they are ready to do the role-play.

Stage Four: Role-play: Students work in pairs and conduct the interview; one joumalist and one eyewitness. They continue doing the role-play. changing partners until each joumalist has interviewed all the eyewitnesses. This can allow for a quick correction slot halfway through if necessary.

Further Activities: A good follow-up to this exercise is a writing exercise which involves all the students writing a letter to their families telling of the horrific events.

b. Vision on/ Sound off

In this particular emotionally charged scene from High Fidelity, three people who work in a record shop have an argument. It is very graphic with plenty of gestures to stimulate the imagination. Good for intermediate levels. Level: Pre-intermediate, Intermediate, Upper intermediate 


\title{
Sound Off/ Vision On and Dubbing
}

Film: High Fidelity (adaptable for other films)

\begin{abstract}
This lesson uses the hilarious record shop argument scene when Barry (Joe Black) brings his Monday morning tape into the shop. The main dialogue is between Rob (John Cusack) and Barry with a little input from Dick (Todd Louiso). Three characters in all. There are a lot a gestures and emotions on show so the students have plenty of scope to work with.
\end{abstract}
From when the camera pans across boxes of singles in the record shop just before Barry's entrance to when Rob talks into the camera.
Stage One: Students watch the scene with the sound off and answer gist questions like:
- Who's the boss?
- Why are they arguing?
- Why does one of them take out a cassette and throw it at the other?
- Why does the other one then run over and switch the record player off?
- Why does he then go up to him and shout in his face?
- What does the guy say to the camera at the end?

Stage Two: Students watch the scene again and predict some the language which may be spoken in the argument. Have them predict six words, for example.

Stage Three: In groups of three, students then write the script for the scene. You may have to re-run the scene several times to help them do this.

Stage Four: Students then take turns to lip-synch the scene standing next to the T.V. This is great fun and students love doing it.

Cooler: Let them watch the original scene and compare it to their own.

Further Activities: Class Oscars. Whose was the funniest? Whose was closest to the original? Whose was the worst? You may want to give prizes for different categories.

\section{RESEARCH METHOD}

The population of this study was all second semester of Nahdlatul Ulama University NTB. Each class has 30-35 students. Class II.Pharmacy.2017 as the experimental class (EG) and class II.Nutritionist.2017 as the control class (CG). There were 19 girls and 15 boys in the EG, and 22 girls and 12 boys in the CG giving a total of 34 students in each of the sample classes.

The data was collected from these second semester students in the 20172018 academic year using a pre-test and a post-test as instruments. The treatments were given for four meetings

\section{RESULTS AND DISCUSSIONS}

in which the EG was taught by using authentic videos as an audio visual aid and the CG, by contrast, was taught using the audio recording usually used by the teacher for teaching listening. In spite of the different methods, both groups had similar materials provided by the researcher.

The data was analyzed statistically to find out whether the hypothesis in this study was accepted i.e. whether the use of authentic video as an audio visual aid effectively enhanced the listening achievements of second grade students from Nahdlatul Ulama University NTB. 
In the table below are the important scores from the pre-tests and the post-tests for both the EG and the CG before and after the treatment.

Table 2. Important Scores from the EG and the CG

\begin{tabular}{|r|c|c|c|c|}
\hline \multicolumn{2}{|c|}{ Experimental Group = EG } & \multicolumn{2}{c|}{ Control Group = CG } \\
\hline \multirow{2}{*}{ No } & \multicolumn{2}{|c|}{ Scores } & \multicolumn{2}{c|}{ Scores } \\
\cline { 2 - 5 } & Pre-test & Post-test & Pre-test & Post-test \\
\hline Median & 60 & 73 & 47 & 63 \\
\hline Highest & 80 & 95 & 76 & 86 \\
\hline Lowest & 40 & 60 & 26 & 43 \\
\hline Spread & 40 & 35 & 50 & 43 \\
\hline Improve ment & & 13 & & 16 \\
\hline
\end{tabular}

\section{A. The Independent T-Test Analysis of the Pre-Test}

The objective of the independent $t-$ test was to find out if there was any significant difference in the listening abilities of the EG and Cg before the treatment. The results from the T-test of the pre-tests are set out in the table that follows:

Table 3. T-Test Results from the Pre-Tests of Both the EG and the CG

\begin{tabular}{|c|c|c|c|c|c|c|c|}
\hline \multirow[b]{3}{*}{$\begin{array}{l}\text { Pretest: } \\
\text { Equal } \\
\text { variance } \\
\text { assumed } \\
\text { Equal } \\
\text { variance } \\
\text { not } \\
\text { assumed }\end{array}$} & \multicolumn{2}{|c|}{$\begin{array}{l}\text { Levene's test for } \\
\text { equality of } \\
\text { Variances }\end{array}$} & \multicolumn{5}{|c|}{ T-test for Equality of Means } \\
\hline & $\mathrm{F}$ & Sig & $\mathrm{T}$ & $\mathrm{df}$ & $\begin{array}{l}\text { Sig. } \\
\text { (2- } \\
\text { tld) }\end{array}$ & $\begin{array}{l}\text { Mean } \\
\text { Diff }\end{array}$ & $\begin{array}{l}\text { Std. Error } \\
\text { Difference }\end{array}$ \\
\hline & 0.04 & 0.84 & 0.49 & 66 & 0.63 & 1.76 & 3.61 \\
\hline
\end{tabular}

The table above shows that tobtain of the pretests from both the EG and the CG was 0.49. The ttable for $\mathrm{df}=66$ at the level of significance of $5 \%(=0.05)$ is 2.00 . Since tobtain $<$ ttable that is $0.49<2.00$, so $\mathrm{H} 0$ was accepted, so there was no significance difference in listening ability between the students in the EG and the CG before the treatment. 


\section{B. The Independent T-Test Analysis of the Post-Tests}

This independent t-test was done to find any significant differences between the post-test results from the EG and the CG. The result of this t-test are set out in the table below:

Table 4. T-Test Results from the Post-Tests of both the EG and the CG

\begin{tabular}{|l|l|l|l|l|l|l|l|}
\hline & $\begin{array}{l}\text { Levene's test } \\
\text { for equality } \\
\text { of Variances }\end{array}$ & \multicolumn{6}{|c|}{ T-test for Equality of Means } \\
\cline { 2 - 7 } & F & Sig & T & df & $\begin{array}{l}\text { Sig. } \\
(2- \\
\text { tld })\end{array}$ & $\begin{array}{l}\text { Mean } \\
\text { Diff }\end{array}$ & $\begin{array}{l}\text { Std. Error } \\
\text { Difference }\end{array}$ \\
$\begin{array}{l}\text { Pretest: } \\
\text { Equal } \\
\text { variance } \\
\text { assumed } \\
\begin{array}{l}\text { Equal } \\
\text { variance } \\
\text { not } \\
\text { assumed }\end{array}\end{array}$ & 0.071 & 0.791 & 3.76 & 66 & 0.00 & 1.76 & 13.10 \\
\hline
\end{tabular}

From these tables, it can be seen that tobtain from the post-tests of both the EG and the CG was 3.76. The table for $\mathrm{df}=66$ at the level of significance $5 \%(=0.05)$ is 2.00 . The result shows that tobtain $>$ table that is $3.76>2.00$, so $\mathrm{H}_{0}$ is rejected. This means that the EG students who were taught using authentic videos performed significantly better than the CG students who were taught using audio materials only.

\section{The Dependent T-Test (Paired T- Test Analysis)}

Table 5. T-Test Result from the Pre-Test and Post-Test Scores from the EG

\begin{tabular}{|c|c|l|l|l|l|l|}
\hline \multirow{2}{*}{} & \multicolumn{2}{|l|}{ Paired Differences } & t & df & $\begin{array}{l}\text { Sig. (2- } \\
\text { tld) }\end{array}$ \\
\cline { 2 - 7 } & Mean & $\begin{array}{l}\text { Std. } \\
\text { Dev }\end{array}$ & $\begin{array}{l}\text { Std. Error } \\
\text { Mean }\end{array}$ & & & \\
\hline $\begin{array}{c}\text { Pair 1 Post-test Control } \\
\text { - pre-test control }\end{array}$ & 25.46 & 12.11 & 2.21 & 11.51 & 34 & 0.00 \\
\hline
\end{tabular}

From the table, it can be seen that the t-test of the EG was 11.51. The t-table for 0.05 ) was 2.04 .

A paired test is applied to determine the differences of the students' achievement both in experimental and in control group before and after giving the treatment. It aims to evaluate the result of dependent-test in experimental group and in the control group. The dependent t-test is obtained by pairing the result of pre-test and post-test score in each class. The data was calculated by using SPSS procedure that can be seen in the following table.

Table 6. T-Test Results from the Pre-Test and Post-Test Scores from the CG

\begin{tabular}{|c|l|l|l|l|l|l|}
\hline & \multicolumn{3}{|l|}{ Paired Differences } & t & df & $\begin{array}{l}\text { Sig. (2- } \\
\text { tld) }\end{array}$ \\
\cline { 2 - 8 } & Mean & $\begin{array}{l}\text { Std. } \\
\text { Dev }\end{array}$ & $\begin{array}{l}\text { Std. Error } \\
\text { Mean }\end{array}$ & & & \\
\hline $\begin{array}{c}\text { Pair 1 Post-test Control } \\
\text { - pre-test control }\end{array}$ & 10.60 & 14.28 & 2.60 & 4.06 & 34 & 0.00 \\
\hline
\end{tabular}

According to the data from the tables, the t-test of the EG was 11.51 and the $\mathrm{t}$ test of the CG was 4.06. The ttable for $\mathrm{df}=34$ at the level of significance $5 \%(=$
$0.05)$ is 2.04. The result confirms that tobtain>ttablefor both groups was 11.51 $>2.04$ for the EG and $4.06>2.04$ for the CG. This shows that both groups 
performed better in listening achievement after the treatment. Nevertheless, the result of the t-test for the EG was significantly larger than the t-test for the CG $(11.51>4.06)$. Thus there was much more improvement in the EG compared to the CG. The EG, taught using authentic video, got a much more significant improvement than the CG, taught using audio compact discs (CD), the usual listening aid used by the teacher for teaching listening. 


\section{CONCLUSIONS AND SUGGESTIONS}

The post-test results and the independent $t$-test from the EG was significantly higher than that from the CG which means that the implementation of authentic video positively influenced the students' listening skills. From the data analysis of the pre-test and post-test obtained from the EG, it can be seen that listening for specific information was the most enhanced listening sub-skill after the application of authentic video as an audio visual aid. Although the other listening sub skills, listening for the main ideas, listening for the gist, and listening for detailed information also increased, listening for specific information improved more significantly than the other listening sub-skills.

Using authentic video in the language classroom can be quite challenging for the students, but it was also more interesting at the same time. This could be due to the fact that using authentic video may bring the content and the subject matter to life for them that enabled them to make important connections in the world beyond the classroom.

According to the analysis of the findings and the discussions, using authentic video as an audio visual aid was a successful method for improving teaching of listening. However, some limitations may arise when applying this aid. The writer suggests further studies be done using a variety of authentic videos in order to obtain more information about their effectiveness for teaching-learning listening as well as for the other English skills in order to enrich our knowledge about the use of authentic video. 


\section{REFERENCES}

Berk, R. A. (2009). Multimedia teaching with video clips: TV, movies, YouTube, and mtvU in the college classroom. International Journal of Technology in Teaching and Learning, 5(1), 121.

Brown, H.D. (2001). Teaching by principles: an interactive approaches to language pedagogy $\left(2^{\text {nd }}\right.$ edition). New York: Longman.

(2000).Principles of language learning and teaching ( $4^{\text {th }}$ edition). New York: Longman.

Cahir, I. (2006). The use of video as an audiovisual material in foreign language teaching classroom. The Turkish Online Journal of Educational Technology TOJET Vol. 5 No. 4

Cahyono, B.Y. \& Widiati, U. (2009). The teaching of efl listening in the Indonesian context: the state of the art. TEFLIN Journal, Volume 20, Number 2, August 2009

Field, J. (2009). Listening in the language classroom. Cambridge: Cambridge University Press.

Flowerdew, J. \& Miller, L. (2005). Second language listening: theory and practice. Cambridge: CUP

Harmer, J. (2007). The practice of english language teaching. (4th edition). Essex: Pearson Education

Kathleen S. M. Chu. (2006). Teaching Listening with videoproduction. In $\mathrm{H}$. Nguyen (Ed.) Computer and video technology in language teaching: A practical guide. TESL Programs, Hawai i Pacific University.Retrieved on May 15, 2006, from www2.hawaii.edu/ htnguyen/CALLind ex.html.

Kusumarasdyati. (2006). Subtitled movie DVDs in Foreign Language Classess. Retrieved on 15 October 2013 from http: aare.edu.au/06pap/kus06105.pdf

McKinnon. (n.d.).Teaching technologies: teaching English using video. Retrieved on 15 October 2012

http://www.onestopenglish.com/support /methodology/teachingtechnologies/teaching-technologiesteaching-english-usingvideo/146527.article

Nunan, D. (1991). Language teaching methodology: a textbook for teachers. New York: Prentice-Hall. (2002). Listening in language learning. In Richards, J.C., \& Renandya, W.A. (Eds.), Methodology in Language teaching: An Anthology of Current Practice (pp. 238-241). Cambridge: Cambridge University Press.

Rahmatian, R.\&Armium, N. (2011). The effectiveness of audio and video documents indeveloping listening comprehension in a foreign language.International Journal of English Linguistics.Vol. 1 No. 1.

Richards, J.C., \& Renandya, W.A. (2002). Methodology in Language teaching: An Anthology of Current Practice. Cambridge: Cambridge University Press.

Rost, M. (2002). Teaching and researching listening. Edinburg: Longman Education

Vandergrift, L. (20007). Recent development in second and foreign language listening comprehension research. Lang. Teach. Vol. 40. 